\title{
Sensing Gestures for Business Intelligence
}

\author{
David Bell, Nikhil Makwana, Chidozie Mgbemena \\ Department of Information Systems and Computing (DISC), Brunel University, London, UK
}

\begin{abstract}
Keywords: $\quad$ Motion Sensors, Gestures, Business Intelligence.
Abstract: The combination of sensor data with analytic techniques is growing in popularity for both practitioners and researchers as an Internet of Things (IoT) offers new opportunities and insights. Organisations are trying to use sensor technologies to derive intelligence and gain a competitive edge in their industries. Obtaining data from sensors might not pose too much of a problem, however subsequent utilisation in meeting an organisation's decision making can be more problematic. Understanding how sensor data analytics can be undertaken is the first step to deriving business intelligence from front line retail environments. This paper explores the use of the Microsoft Kinect sensor to provide intelligence by identifying and sensing gestures to better understand customer behaviour in the retail space.
\end{abstract}

\section{INTRODUCTION}

Organisations generate vast amounts of data from their day to day operations (McRobbie, et al., 2012; Vera-Baquero, et al., 2013). From these data sources, some organisations are able to harvest insightful information termed Business Intelligence (BI) (Feng \& Liu, 2010). It has evolved into a set of computer based techniques used to identify, extract and analyse business data to better understand current business trends and more importantly predict future business patterns in order to gain competitive advantages and effectively take steps to deliver better performances. Globally dispersed customers and extended supply chains have further motivated the use of BI. Clearly, key data from customers moving around the commercial environment is missing when only focusing on completed purchasing etc.

Importantly though, with a growing Internet of Things (IoT) making our environment smarter, it provides opportunities to analyse data that is generated from smart objects such as sensors (Doody \& Shields, 2012). Increasingly, businesses are discovering that environments and machines augmented with sensors are able to send information back to headquarters that once analysed can provide a competitive advantage (Hewlett-Packard, 2013). Making sense of the plethora of data generated by such devices and leveraging reality mining applications (Doody \& Shields, 2012) can provide an ability to extract useful knowledge from real world sensor data and provide the basis to identify predictable patterns. Sensor applications are widely reported in literature with examples of location technology and smartphone devices used to request cabs, effectively saving cab drivers valuable time and money in looking for fares (Hailo, 2013). Within retail industries, footfall sensors are used to provide intelligence for staff scheduling that ensure customer demands are met without overheads being excessive (Ipsos, 2013). Together with an overall trend in Point-of-Sale (POS) transactions, loyalty cards used by major retailers are being utilised to track customer purchases leading to a greater understanding of shopping habits and enabling businesses to track the success of marketing initiatives (Zakaria, et al., 2012).

Despite uncovering a wealth of data about shopper demographics and their purchase history, insight into the customers in store behaviour is often missing. Understanding where customers spend most of the time when within a store, identifying which products and promotional displays are most popular, how long customers wait in lines etc. can address this lack of 'front-line' knowledge. This paper explores how motion sensors be used to better understand the retail environment. Leveraging motion sensing technology provides the ability to precisely track customers and observe human behaviour for pattern 
analysis and business intelligence (Cao, 2008). The paper reports on related work in both motion sensing and business intelligence before coverage of our specific pattern sensing approach and framework. A practical experiment is then presented that leads to our BI architecture discussion and concluding remarks.

\section{RELATED WORK}

Two areas of interest in this research paper are Business Intelligence (BI) and Motion Sensors technology. In light of this, the purpose of this section is to highlight business intelligence currently used by businesses and identify architectures used in case studies. Secondly, research on motion sensors is used to identify suitable sensors that are able to provide motion data to a business intelligence framework.

\subsection{Business Intelligence}

Luhn coined the term 'Business Intelligence' (BI) in 1958 (Luhn, 1958). He defined BI as "the ability to apprehend the interrelationships of presented facts in such a way as to guide actions towards desired goals" (Luhn, 1958, pp. 314-319). Despite having less significance at the time (when compared to its relevance today), this key work underpins the theory and practice of decision support systems. The work carried out by Luhn has been fundamental in providing reporting, Online Analytical Processing (OLAP) and visualisation capabilities used business decision making today. As a modern day term, BI is used to describe the collection of processes, tools and technology helping in achieving more profit through improving productivity, sales and services of an enterprise. With the aid of BI methods, corporate data can be better analysed and transformed into useful knowledge, which in turn is required to achieve a profitable business action (Martin, et al., 2012). Modern day business intelligence tools include applications such as Executive Information Systems (EIS), Customer Relationship Management (CRM) and Corporate Performance Management (CPM) (Tvrdikova, 2007). What all of these commercial applications have in common is the ability to use multidimensional data stores that have the benefits of reporting rapid changes as opposed to waiting on batch jobs that run overnight. However, despite their rapid response to change, drawbacks include increased complexity (Vassiliadis, 1998) and maintenance.

Business Intelligence systems are often regarded as business critical solutions and invaluable tools, adding significant value to an enterprise. These systems have often become of paramount importance and are now considered a vital tool for day-to-day business (Xu, et al., 2007). The main purposes of employing business intelligence tools are to provide the right information to the right people at the right time, with the overall aim of allowing effective decision making to take place (Xu, et al., 2007; Krneta, et al., 2008). Many examples of successful BI implementation include Netflix (an on-demand internet streaming media provider) that leverage analytics to analyse customer behaviour to better serve its subscriber base by recommending the right options for their viewers (Microstrategy, 2013). Carphone Warehouse (an independent retail telecommunications provider) utilise business intelligence reporting tools for making decisions such as adjusting headcount based on footfall traffic and conducting in store employee reviews for tracking performance (Computing, 2012). Barclays Bank has employed the use of BI systems to reduce operational costs helping them in efficient recruitment planning and training schedules (Ridgian, 2011).

$\mathrm{BI}$ is a necessity in the retail industry. It is an essential element when realising typical in store activities such as those that further identify potential intelligence that could be used to provide competitiveness. Burke (2002) identifies consumer behaviours such as: 1) Entering the store, 2) entering a specific aisle, 3) checking out and paying for items, and 4) post purchase of customer service (Burke, 2002). These behaviours highlighted by Burke (2002) are also applicable to telecommunication retail environments however consumers are viewing either live or dummy phones (PhoneDog Media, 2013).

Many organisations now rely on and are heavy users of Business Intelligence systems. Tesco for example, is a multinational supermarket and now rated as the second most powerful retailer on the planet. A primary factor in their success is having BI systems that enable them to gather data and analytical skills to test ideas and turn insights into customer and business relevant actions (Advanced Performance Institute, 2013).

Leonidas, et al. (2012) present a middleware framework named 'PLATO' to provide business intelligence applications. "The main goal is to 
provide a framework for the development of applications involving heterogeneous sensors" (Leonidas, et al., 2012, pp. 266-270). The framework supports collection, processing and analysis of the data originating from sensors while enabling the development of business intelligence. Wang, et al., (2012) present a system that obtains the characteristic travel behaviour of an urban population and builds a framework using large scale transportation datasets to extract value added information with the ultimate aim of reducing fuel consumption, improving customer satisfaction and business performance. Hondori et al., 2012 present a tele-rehabilitation study that monitors post stroke patients using sensor technology to provide intelligence in monitoring their activities of daily living and progress in a home environment. Despite many studies presenting research from post stroke patients using wearable sensors, (O'Keeffe, et al., 2007; Zhang, et al., 2012; Hester, et al., 2006), there are many reported drawbacks including the wearable sensor being obtrusive, heavy, costly and generally inconvenient (Benning, et al., 2007; Hondori, et al., 2012). Hondori, et al., 2012 has leveraged motion sensor technology using a Kinect sensor which is completely wireless and a non-wearable technology that provides a more natural experience to sense the health status of the patient (Hondori, et al., 2012).

\subsection{Motion Sensing}

"Motion detection is the fundamental process of detecting whether any entities exist and are moving around the area of interest" (Xiao, et al., pp. 229235). The motion sensor/detector is a converter that measures a physical quantity and coverts it into a signal form which can be read by an electronic instrument.

Various sensors exist for different purposes such as accelerometers, gyroscopes and magnetometers. Accelerometers are a type of device that measures the acceleration. The modern day use of accelerometers can be seen in user interface control on smartphone technology as the tilting motion is used to differentiate between portrait and landscape. A gyroscope can be used to either measure, or maintain, the orientation of a device. Unlike an accelerometer, which measures the linear acceleration of the device, a gyroscope measures the orientation directly. Gyroscope technology has created the ability of making the gaming experience as real as possible. Magnetometers measure the ambient magnetic field and provide digital compass like applications on smartphone devices. These are also more traditional sensors which are small and come at a reasonable cost (Amma, et al., 2010) when compared to smartphones or tablets. The first generation of sensors included pen based and hand worn sensors known as 'data gloves.' However, the latter form of these sensors has limitations such as the feeling of unnaturalness, obtrusive and generally a burden to wear (Ren, et al., 2013). In contrast to the data gloves, and with the recent advancements in HCI and motion sensor technology, many products have surfaced, repurposing traditional sensing technology into new forms. This is more prevalent in gaming systems such as the Nintendo Wii Remote, PlayStation Eye/Move and the Microsoft Kinect for Xbox; each offering a more natural experience and touch free way of communication.

The Microsoft Kinect sensor, released in 2010 for the Xbox, enables users to control and interact with the Xbox 360 without the need for any physical interaction of game controllers. This is realised by the use of a natural user interface and using gestures and spoken commands (Microsoft Corporation, 2013). In contrast, the Wiimote and PS Move require physical contact for navigation. In 2011 Microsoft released a non-commercial software development kit (SDK) for the Kinect sensor allowing developers to build natural, intuitive computing experiences using $\mathrm{C} \#, \mathrm{C}++$ and Visual Basic programming languages.

\section{SENSING PATTERNS}

This research project employs an objective-centred approach to the Design Science Research Methodology (DSRM) as outlined by Peffers et al. (2007). The design problem is identified from the literature review and in this case includes a lack of smart analysis when providing business intelligence in a 'front-line' retail space. Older technology is still being used with an over-reliance on EPOS systems and data. Our design explores how recent gaming sensors can provide more effective sensory input with a specific focus on people in the retail environment.

\subsection{Sensing Architecture}

A high level architectural overview is presented in Figure 1. The framework separates the collection of sensor data from a gesture analysis and codification phase. A sensor augmented environment is able to provide a basis for gesture identification rules. Once 
identified, the gestures can be measured and reported by a BI system.

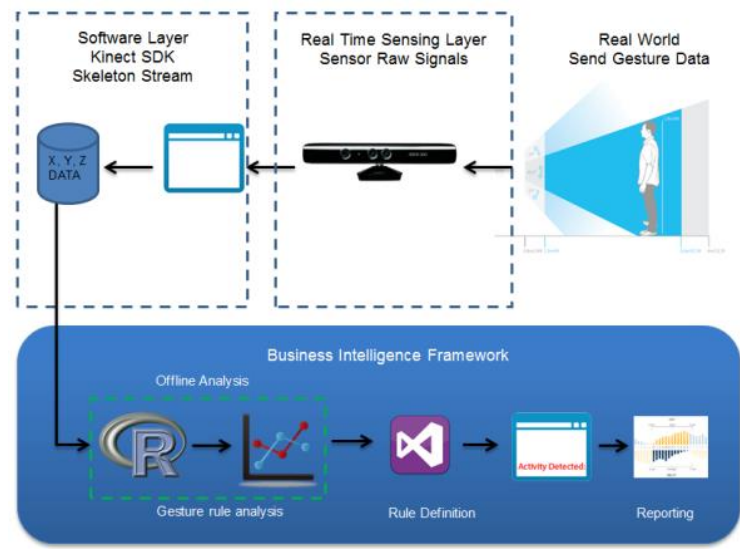

Figure 1: High Level Architecture

The user is free to use their natural interactions in the retail environment which includes activities such as viewing in-store adverts, paying for products at a cashier till and extracting dummy phones for closer viewing. The Kinect sensor (from Microsoft) captures these movements/gestures with the help of the Kinect SDK. The depth stream available to the Kinect sensor is used to process the depth data to generate skeleton data of human body joints, which is stored as $\mathrm{X}, \mathrm{Y}$ and $\mathrm{Z}$ values using the $\mathrm{C \#}$ application created into a text file. Offline analysis of the raw co-ordinate dataset is analysed (with the use of R) to highlight rules that can automatically identify user gestures. Observed analysis results are then written into the sensing application to identify only the rules identified from the analysis in order to provide meaningful business intelligence of customer activity.

\subsection{Sensor Data Capture}

In order to capture a customer's natural interaction in a retail space, a Kinect application has been developed as shown in Figure 2. The user interface has been kept relatively simple as this design phase is focusing on the framework processes required to undertake this new form of BI analysis. The main functionalities of the application:

- Provide 3 streams (RGB, Skeleton and Depth) to provide visual feedback to the user for calibration purposes.

- Seated mode option to capture the top half of skeleton (10 joints)

- Kinect elevation angle to also provide in calibration purposes.
- Capture button, to provide the saving of tracked skeleton body co-ordinates to a data file.

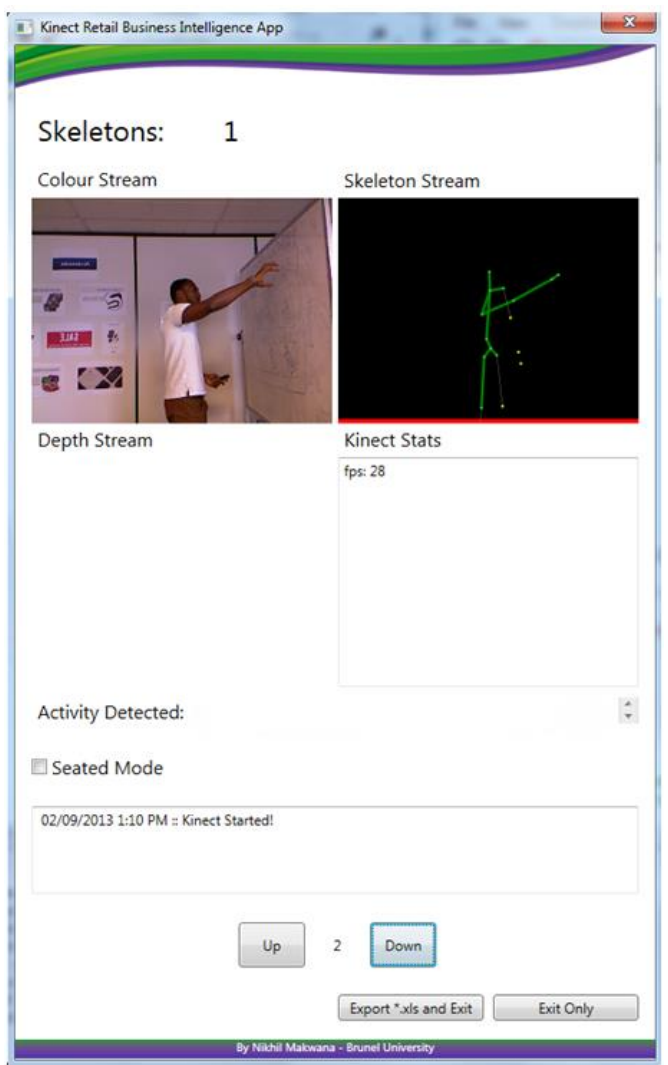

Figure 2: Sensor Data Capture Application

The Kinect sensor provides an easy to use API and ready access to co-ordinates for each part of the body, e.g. elbow_right.Position.X. Initially, these co-ordinates are collected and stored in a data file for rule identification.

\subsection{From Data to Gestures}

The popular $\mathrm{R}$ software environment is typically used for statistical computing and graphics. $\mathrm{R}$ has been used in this research project for statistical analysis and primarily visualisation of the body coordinates that have been captured from Kinect sensors in the retail environment. Command line scripting is used for the analysis of sensor data and rule identification. A third party package 'ggplot2' has been utilised in $\mathrm{R}$ to provide graph building capabilities.

Although we have built a system with a single sensor, it is envisaged that the same approach will allow for multiple sensors in many retail environments. Importantly, an IoT that connects 
many motion sensors requires an architecture that is able to identify gestures before forwarding to integrated reporting platforms.

Table 1 - R Code Descriptions

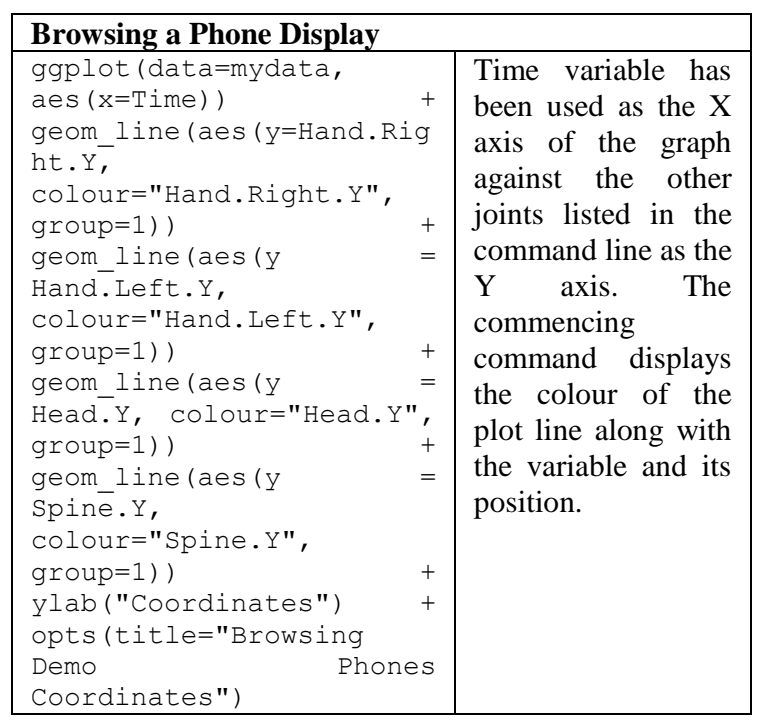

The resulting visualisations of sensor data allow the programmer or data analyst to identify rules for specific customer actions (gestured)- e.g. Browsing and reaching for a phone. The graphical output can be seen in Figure 3 and includes joints co-ordinates in different colours. Rules identified in this process are then coded within the same application presented in Figure 2, adding the recorded gesture to the output data file. Once coded, the application is now ready to capture gestures for use in BI analysis and reporting. The Kinect sensor and application can now be started in the retail space.

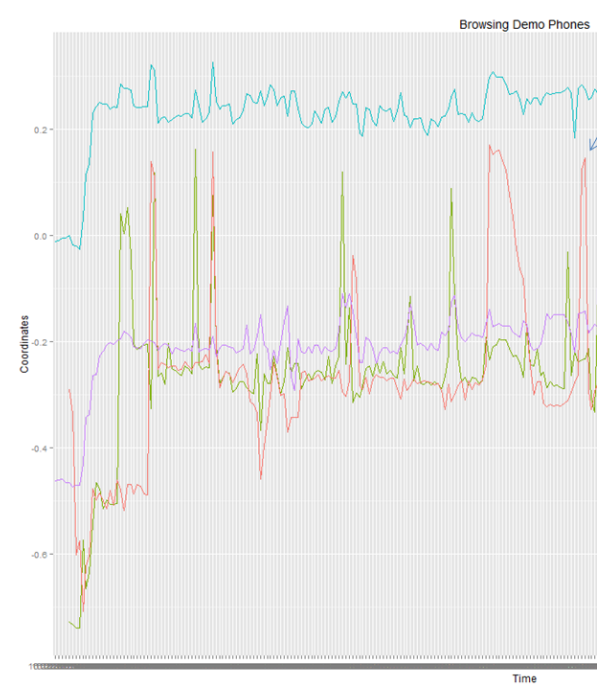

Figure 3: Sensor Data Visualisation

\section{EXPERIMENATION}

Instantiations operationalize constructs, models and methods (March \& Smith, 1995) - typically creating a working implementation. Here we can use the implementation to evaluate the effectiveness of the design - a new sensor driven BI framework.

\subsection{Retail Business Context}

The aim of the lab experimentation was to define gestures in terms of skeletal joint movement through subject's natural interactions via the use of motion capture. Encompassed within this is the identification of gesture rules (e.g. the heuristics for gesture identification). The experiment took place in the lab environment (see Figure 4). The aim of the lab environment is to simulate a real world shopping (Mobile Telephone Shop) experience for the purposes of capturing interactions. A whiteboard has been used to simulate a phone wall display, Point of Sale $(\mathrm{PoS})$ cashier and a gaming experience. A wall has been used to display phone advertisements for subjects to browse. A Kinect sensor has then been mounted on top of a PC monitor, which provides motion sensing capacities that capture the subject standing in the simulated store environment. The sensed user will have their skeleton joints captured for motion activity and will be saved in a text format as it allows interoperability with other applications.

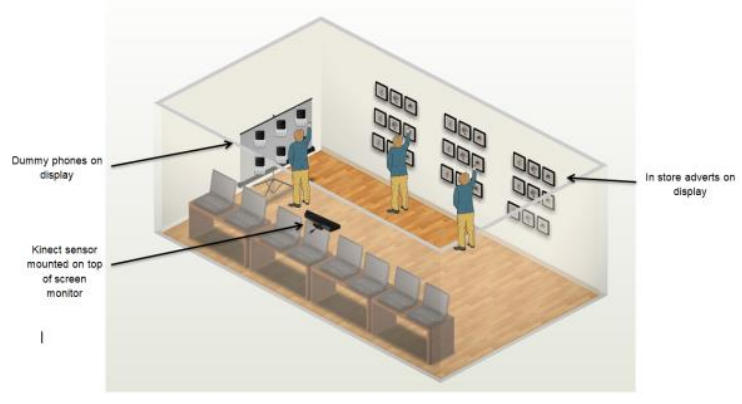

Figure 4: Simulated Retail Environment

\subsection{Captured Data}

A number of scenarios were tested in the simulated environment in order to: 1) Capturing data with the application, 2) analyse the data in order to identify rules, 3 ) code the rules in the applications and then 
4) capture gestures. The scenarios (and rules) can be seen in Table 2. Importantly though, it is the observation of humans early in this process that allow for systematic analysis of key activities - and their associated gestures.

Table 2 - Scenarios and rules identified

\begin{tabular}{|c|c|}
\hline Scenario & Rule \\
\hline Viewing In store Ads & $\begin{array}{l}\text { Either hand extending out } \\
\text { for small constant period. } \\
\text { Hand extending outwards } \\
\text { at the same position as the } \\
\text { head. }\end{array}$ \\
\hline Playing Console Games & $\begin{array}{l}\text { Head and spine joint stay } \\
\text { roughly in the same } \\
\text { position throughout } \\
\text { activity. } \\
\text { Sudden spikes of hands } \\
\text { going up indicate a process } \\
\text { of celebration as well as } \\
\text { expression of sadness when } \\
\text { losing in game. }\end{array}$ \\
\hline $\begin{array}{l}\text { Returning Product at } \\
\text { Cashier }\end{array}$ & $\begin{array}{l}\text { The right hand is observed } \\
\text { to move in front of spine } \\
\text { and upwards towards the } \\
\text { counter for a moment } \\
\text { (returning the product). } \\
\text { The right hand is observed } \\
\text { again to move in front of } \\
\text { spine and upwards towards } \\
\text { the counter which identifies } \\
\text { the payment process. }\end{array}$ \\
\hline $\begin{array}{l}\text { Paying for Product at } \\
\text { Cashier }\end{array}$ & $\begin{array}{l}\text { The right hand is observed } \\
\text { to be extracted near to both } \\
\text { hips possibly indicating } \\
\text { reaching for wallet. } \\
\text { Right hand is then seen in } \\
\text { front of spine which } \\
\text { suggests a payment is in } \\
\text { progress (handing card over } \\
\text { to assistant) this is also } \\
\text { indicated by a period of } \\
\text { stability as the right hand is } \\
\text { raised indicating a } \\
\text { payment. }\end{array}$ \\
\hline Browsing Demo Phones & $\begin{array}{l}\text { Left/Right hand is shown } \\
\text { progressing away } \\
\text { considerably far from the }\end{array}$ \\
\hline
\end{tabular}

\begin{tabular}{|l|l|}
\hline & $\begin{array}{l}\text { head (reaching and } \\
\text { extracting demo phones } \\
\text { from display). } \\
\text { Right hand is then settled } \\
\text { immediately in front of } \\
\text { head as it is being viewed. }\end{array}$ \\
\hline Discussion on Shop floor & $\begin{array}{l}\text { Left/Right hand shows } \\
\text { movement that is directly } \\
\text { beside of spine. Right hip } \\
\text { seen mostly in one place, } \\
\text { also replicated behaviour in } \\
\text { the spine. } \\
\text { Right hand is extracted } \\
\text { down next to right hip. }\end{array}$ \\
\hline
\end{tabular}

The various joints of the body are analysed to uncover rules for scenario actions. These are then coded within the capture application.

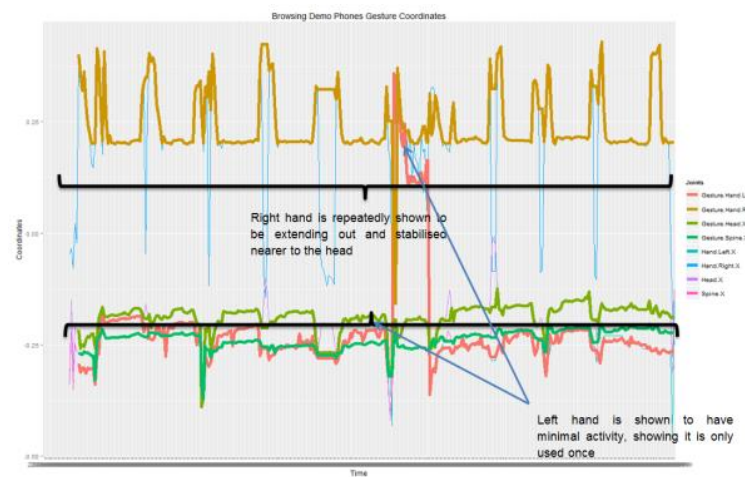

Figure 5: Sensor Visualisation for rule identification

The resulting system, with rules encoded, is able to then capture that data necessary for BI reporting. Iterating through each scenario resulted in a framework for sensor data analysis and codification (presented in Table 3).

Table 3 - Sensor BI Framework

\begin{tabular}{|l|l|}
\hline Process & Description \\
\hline Platform & $\begin{array}{l}\text { A motion capture solution is created or } \\
\text { acquired to support the capture of } \\
\text { customer's natural interaction by } \\
\text { tracking their skeleton movement. }\end{array}$ \\
\hline $\begin{array}{l}\text { Skeletal } \\
\text { Capture }\end{array}$ & $\begin{array}{l}\text { A motion sensor placed in the retail } \\
\text { environment captures customer's } \\
\text { natural form of interaction. The capture } \\
\text { produces full bodily coordinates that } \\
\text { will be stored for post capture analysis. }\end{array}$ \\
\hline $\begin{array}{l}\text { Post- } \\
\text { capture } \\
\text { Human }\end{array}$ & $\begin{array}{l}\text { Joint coordinates are visualised in a } \\
\text { graph form in order to identify trending } \\
\text { patterns on the different bodily skeletal }\end{array}$ \\
\hline
\end{tabular}




\begin{tabular}{|l|l|}
\hline Analysis & $\begin{array}{l}\text { joints. The trends provide a means to } \\
\text { define gesture rule identification. }\end{array}$ \\
\hline $\begin{array}{l}\text { Rule } \\
\text { Codification }\end{array}$ & $\begin{array}{l}\text { The rules identified from the post } \\
\text { capture analysis are implemented into } \\
\text { the capture application, enabling the } \\
\text { capture to identify gestures triggered } \\
\text { by subject's natural interaction. }\end{array}$ \\
\hline Recapture & $\begin{array}{l}\text { A motion sensor is placed in the retail } \\
\text { environment that captures gestures } \\
\text { (based on the earlier rule } \\
\text { identification). }\end{array}$ \\
\hline $\begin{array}{l}\text { End of Day } \\
\text { (EOD) } \\
\text { Business } \\
\text { Intelligence } \\
\text { Reporting }\end{array}$ & $\begin{array}{l}\text { Aggregated gestures identification } \\
\text { reports are produced for viewing by } \\
\text { managers/stakeholders (or integration } \\
\text { with other data sources within a BI } \\
\text { tool) }\end{array}$ \\
\hline
\end{tabular}

\subsection{Business Intelligence}

A number of visualisations were developed for illustrative purposes. Primarily to put the data capture process in a business context. A sample of these is shown in Figure 6. The textual output was easily loaded into commercial grade BI reporting products (which is our case was Tableau).

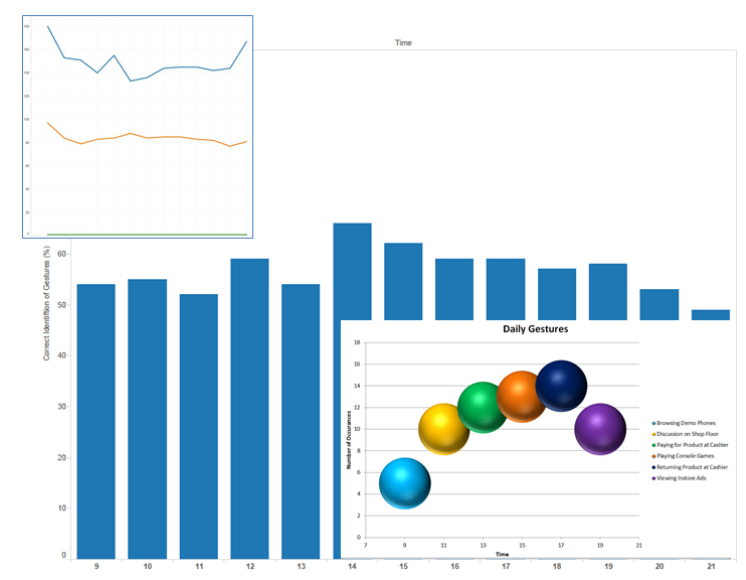

Figure 6: BI Reporting

Experimenting with our business intelligence views and using a new group of human subjects, a bar chart depicting hourly recognised gestures has been created to identify the success rate of gesture recognition (\%) throughout the day. The average identification success rate is just over $50 \%$. Although disappointing, this was largely due to the Kinect application calibrated for the few subjects that took part in the initial test. Despite this, the framework has proved effective 'in use' and offers interesting possibilities when part of a wider business intelligence environment, linking data with further data sources.

\subsection{Discussion and Evaluation}

The paper has made a contribution in the research area of motion sensing in a retail space environment. Utilising the Natural User Interface (NUI) paradigm commonly found in the gaming industry and applying it in a retail setting is an effective means of business. This paper has identified that commodity sensor hardware, which in this case is the Kinect motion sensor, offers a novel approach to providing strategic organisational insights into customer activity in the field. This could offer substantial competitive benefits. The production of business intelligence reports provides additional assistance to the traditional POS reporting methods currently relied upon and promote new intelligence gathering perspectives. The research also provides a novel framework for providing business intelligence with ability to be adapted for different domains. The research contributions of this research paper can be extended to be applied practically in other domains, for example the health sectors and specifically telehealth for purposes such as monitoring of poststroke patients.

\subsection{Future Research}

There is scope for this research to be progressed further to form part of the larger business intelligence platform. During the development phase, areas of further work were identified:

1) Social Media - The rise of 'citizen sensor networks' provides an opportunity to understand and analyse data reported by citizen sensors and the fusion of this data with the gesture sensed data to identify further potential trends. Gathering intelligence in this manner may be able to add a new perspective, identifying novel business intelligence (combining physical action and opinion).

2) Data repositories - With the aforementioned fusion of social data, data repositories stored by organisations such as transaction histories, customer data, and internal ERP systems can also be integrated and fused into the sensed data which then gives the possibility of building customer profiles from past data. Data gathered can be used by many departments in for-profit organisations, such as marketing departments for effective use of advertising. 
3) Multiple sensors - Employing the use multiple Kinect (or other) sensors and fusing the captured date from the sensors is highly likely to enhance the accuracy of the results obtained.

\section{CONCLUSION}

This paper presents an approach for monitoring and understanding customer behaviour in-store using motion sensors. In the design experiment presented, users performed natural activities in a retail space that included actions such as browsing phones, viewing ads and paying for products at the cashier till. The experiment was carried out in a lab environment with posters of phones, ads and cashier point to simulate a retail space. A Kinect sensor was used to capture movements and $\mathrm{R}$ was used to define rules which automatically captured user gestures. A framework is outlined that separates the capture of motion from the gesture identification and business intelligence reporting. A number of interesting avenues of further research are apparent from our exploratory work - adding intelligent data analysis to automatically identify rules as well as integrating related data sets.

\section{REFERENCES}

Advanced Performance Institute, 2013. Business Intelligence (BI) - What is BI? Training, examples \& case studies:. [Online]

Available at:
institute.com/Business\%20Intelligence.html
[Accessed 25 July 2013].

Amma, C., Gehrig, D. \& Schultz, T., 2010. Airwriting Recognition using Wearable Motion Sensors. ACM, pp. 1011.

Benning, M. et al., 2007. A Comparative Study on Wearable Sensors for Signal Processing on the North Indian Tabla. Communications, Computers and Signal Processing.

Burke, R. R., 2002. Technology and the customer interface: what consumers want in the physical and virtual store. Journal of the Academy of Marketing Science.

Cao, L., 2008. Behavior Informatics and Analytics: Let Behavior Talk. Data Mining Workshops.

Computing, 2012. Case Study: Business intelligence at Carphone Warehouse - 23 Aug 2012 - Computing News:. [Online]

Available at: http://www.computing.co.uk/ctg/news/2200696/case-studybusiness-intelligence-at-carphone-warehouse
[Accessed 02 September 2013].

Doody, P. \& Shields, A., 2012. Mining Network Relationships in the Internet of Things. ACM.

Feng, Y. \& Liu, Y., 2010. Design of the Low-Cost Business Intelligence System Based on Multi-agent. Information Science and Management Engineering (ISME).

Hailo, 2013. HAILO. The Black Cab App:. [Online] Available at: https://www.hailocab.com/ [Accessed 1 September 2013].

Hester, T. et al., 2006. Using Wearable Sensors to Measure Motor Abilities following Stroke. Wearable and Implantable Body Sensor Networks.

Hewlett-Packard, 2013. From the Internet of Things, a business intelligence bounty - HP Software Discover Performance: [Online]

Available at: http://h30458.www3.hp.com/us/us/discoverperformance/info-management-leaders/2013/apr/from-theinternet-of-things--a-business-intelligence-bounty.html [Accessed 1 September 2013].

Hondori, H. M., Khademi, M. \& Lopes, C. V., 2012. Monitoring Intake Gestures using Sensor Fusion (Microsoft Kinect and Inertial Sensors) for Smart Home Tele-Rehab Setting. IEEE.

Ipsos, 2013. Why count customers? | Experts in retail footfall counting | IPSOS Retail Performance: [Online] Available at: http://www.ipsosretailperformance.com/WhatWeDo/WhyCountCustomers [Accessed 01 September 2013].

Krneta, D., Radosav, D. \& Radulovic, B., 2008. Realization business intelligence in commerce using Microsoft Business Intelligence. Intelligent Systems and Informatics, pp. 1-6.

Leonidas, P., Drakoulis, D., Dres, D. \& Smailis, C., 2012. PLATO - Intelligent Middleware Platform for the Collection, Analysis, Processing of Data from Multiple Heterogeneous Sensor Systems and Application Development for Business Intelligence. Informatics (PCI).

Luhn, H. P., 1958. A Business Intelligence System. IBM Journal of Research and Development, Volume 2, pp. 314319.

March, S. T. \& Smith, G. F., 1995. Design and natural science research on information technology. Decis. Support Syst., Volume 15, pp. 251-266.

Martin, A., Lakshmi, M. \& Prasanna Venkatesan, V., 2012. An analysis on business intelligence models to improve business performance. Advances in Engineering, Science and Management (ICAESM), pp. 503-508.

McRobbie, G., Talati, S. \& Watt, K., 2012. Developing 
business intelligence for Small and Medium Sized Enterprises using mobile technology. Information Society (iSociety).

Microsoft Corporation, 2013. Product Features | Microsoft Kinect for Windows: [Online] Available at: http://www.microsoft.com/enus/kinectforwindows/develop/sdk-eula.aspx

[Accessed 20 July 2013].

Microstrategy, 2013. MicroStrategy-Mobile-BI-Retail-

Apps.pdf:. [Online]

Available at:

https://www.microstrategy.com/Strategy/media/downloads /products/MicroStrategy-Mobile-BI-Retail-Apps.pdf

O'Keeffe, D. T., Gates, D. H. \& Bonato, P., 2007. A Wearable Pelvic Sensor Design for Drop Foot Treatment in Post-Stroke Patients. Engineering in Medicine and Biology Society.

PhoneDog Media, 2013. How important are display models in wireless retail stores? | PhoneDog:. [Online] Available at: http://www.phonedog.com/2013/04/23/howimportant-are-display-models-in-wireless-retail-stores/ [Accessed 02 September 2013].

Peffers, K., Tuunanen, T., Rothenberger, M. A. \& Chatterjee, S., 2007. A Design Science Research Methodology for Information Systems Research. J. Manage. Inf. Syst., Volume 24, pp. 45-77.

Ren, Z., Yuan, J., Meng, J. \& Zhang, Z., 2013. Robust PartBased Hand Gesture Recognition Using Kinect Sensor. Multimedia, IEEE Transactions on, Volume 15, pp. 11101120.

Ridgian, 2011. RidgianBarclaysYourPeopleCS.pdf:. [Online] Available at: http://www.ridgian.co.uk/downloads/RidgianBarclaysYourP eopleCS.pdf

[Accessed 03 September 2013].

Tvrdikova, M., 2007. Support of Decision Making by Business Intelligence Tools. Computer Information Systems and Industrial Management Applications, 2007.

Vassiliadis, P., 1998. Modeling multidimensional databases, cubes and cube operations. Scientific and Statistical Database Management.

Vera-Baquero, A., Colomo-Palacios, R. \& Molloy, O., 2013. Business process analytics using a big data approach. IT Professional.

Wang, C. \& Chen, H., 2012. From data to knowledge to action: A taxi business intelligence system. s.l., Information Fusion (FUSION).

Xiao, J. et al., 2012. FIMD: Fine-grained Device-free
Motion Detection. Parallel and Distributed Systems (ICPADS), pp. 229-235.

Xu, L. et al., 2007. Research on Business Intelligence in enterprise computing environment. Systems, Man and Cybernetics, pp. 3270-3275.

Zakaria, I., Rahman, B. A. \& Othman, A. K., 2012. The relationship between loyalty program and customer loyalty in retail industry: A case study. Innovation Management and Technology Research (ICIMTR).

Zhang, Z., 2012. Microsoft Kinect Sensor and Its Effect. MultiMedia, IEEE, pp. 4-10. 